\title{
Analysis on the Function of Cultural Connotation in Vocabulary Teaching and Learning of English Majors
}

\author{
Xianmei Sun \\ Dept. of Foreign Languages, Dezhou University, Dezhou, 253023, China \\ Email: sxm1964@126.com
}

\begin{abstract}
Vocabulary is one of most important essentials of language, and it is also the basic of language communication. There are great differences between Chinese and English culture. Therefore, this difference will certainly reflect on the words, especially words with special cultural connotation. In English, there are a lot of words with cultural connotation. University English students who do not understand English culture will certainly misunderstand its cultural connotation because of the negative transfer of culture. This paper will discuss the relations between culture and vocabulary and the problems caused by different cultural connotations, and thus puts forward some suggestions on how to improve vocabulary understanding in intercultural communication of English majors.
\end{abstract}

Index Terms — cultural connotation, cultural differences, vocabulary teaching

\section{INTRODUCTION}

If language structures make up the skeleton of a language, it is vocabulary that provides the vital organs and the flesh. Vocabulary is one of the most important essentials of language, and it is also the basis of language communication. In vocabulary researches, vocabulary refers not only to single words, but also phrases and idioms. And in the Oxford Advanced Learner's English-Chinese Dictionary, the definition of the "vocabulary" is the total number of the words that make up a language. It is the basic meaningful unite in language communication.

As language has a close relation with culture, culture learning plays an important role in learning language. For a long time, teachers in university English teaching and learning only pay much attention to the pronunciation, the basic meaning of words, but without paying attention to the cultural learning. The lack of cultural background causes carrier in students' understanding words well. Therefore, cultural learning should be put on a more important place in the future vocabulary teaching and learning.

\section{RELATIONSHIP BETWEEN CULTURE AND VOCABULARY}

Culture, totality of mental and material wealth through human's history, is the product of people's practice and creation. Any race in the world has its own culture and language. Language serves as the window to manifest the content of its own culture. Likewise, culture, attached to language, is regarded as the cradle of its own race speeches. In linguistic aspect, language is the reflection of its own culture.

As is widely known, vocabulary, the building material, is essential to a language. It is one of the three basic components (pronunciation, vocabulary and grammar), and is of utmost importance to people's communication and language learning. Language emerges first as words, and the coining of new words never stops. Pronunciation and grammar are presented by vocabulary. The linguist David Wilkins (1972) once summered up the importance of vocabulary in his book Linguistics and Language Teaching: "Without grammar very little can be conveyed, without vocabulary nothing can be conveyed." To achieve the purpose of communication, people need to learn vocabulary first.

Just as the famous linguist Chen Yuan (1983)says vocabulary is the most active and dynamic element that sensitively reflect the social changes in life and thinking. Different cultures give words specific and particular signs, symbols and culture connotation. Only in the certain culture environment can the word be correctly understood and furthermore the communication be successful. The hierarchy of lexicon is the mirror of the nation's culture, and through the hierarchy of lexicon some of the nation's culture is transmitted and recognized by the language users.

Since there are great differences between the English culture and Chinese culture in the aspects of values, morality, religion, customs and so on. These different national cultures give the words different culture connotations. Take the common color words "red", "white", "black" for example. "Red", "white" and "black" is three kinds of colors and each of them refers to the same color in English and in Chinese. But the differences of people's attitudes, beliefs, values give the three colors different associative meaning and cultural connotation.

Both in English and in Chinese, red is connected with congratulation and ceremony. For example, there is "red-lettered days" in English which refers to holidays. Especially in China, red is also referred to revolution or 
something with active meaning. However, the color red in English is not only an active word, it also refers to the negative aspects. For example, "red flag" means something that makes people angry. "See red" means somebody is so angry that he even gets mad. "In the red" is a phrase concerns with business with the meaning "be in debt". The color red also refers to the dangerous state, as in the phrase "red light".

There is a viewpoint in China that the color "white" is concerned with the connotation of inauspicious. In a funeral, relatives wear white mourning apparel to show the sad mood to the dead. While in the eyes of westerners, white is the color that symbolizes lucky and purity. The bride wears white wedding clothes in their wedding ceremony to show their loyalty. There are also phrases like "a white day" and "a white lie". The former means a lucky day and the later means a lie without intention.

In English, black is the word with some negative meaning. "Black lie", for example, is not the same with "white lie" but means a lie with vicious intention, i.e. slander. There are also words like blackguard, black list, black mark and so on. Blackguard, as we know, means scoundrel. In the sentence "John is blacklisted", blacklist means somebody is to be wanted by the police. However, black in English can be referred to something active. Take the phrase "in the black" foe example. It is a phrase often used in business. Opposite to the phrase "in the red", it means the company has a net profit. In English countries, the color of ink which is used to record the profit is black, thus the phrase "in the black" got its meaning.

As Liu Shuang (1995, 4)in his essay says culture makes us to have associative meaning towards the specific symbol. It changes the word's meaning and enables us to understand the word's connotation. Since the knowledge and beliefs that constitute a people`s culture are habitually encoded and transmitted in the vocabulary, it is extremely difficult to separate the two.

As the relationship between culture and vocabulary is so close, it is impossible to teach vocabulary well without telling students its cultural factors. Vocabulary is both the carrier and the container of culture.

\section{PROBlems CAUSED By DifFERENT CULTURAL CONNOTATION IN VOCABULARY UNDERSTANDING}

There are many vocabularies in one culture can't find equal equivalence in another culture. Because of the differences, there are many misunderstanding in their understanding .There are also different world outlooks, values and culture consciousness in different cultures. So this will also cause misunderstanding in teaching and learning of a language.

\section{A. Color Differences}

Color terminology has also been used to explore the relationship between different languages and cultures. In this section, the cultural associations of certain colors will be discussed, with "colorful" phrases and expression is both English and Chinese used as illustration.

Red This color is usually associated with celebrations and joyful occasions; this is true in English-speaking countries as well as China. So in English one finds, for example, red-letter days----holidays such as Christmas and other special days. Such days are printed in red on calendars, rather than in black for ordinary days. In Chinese here is an example of 红双喜, 开门红. The color red is symbol of good fortune. Red is also associated with certain emotions. In English , to become red-faced shows embarrassment, as it dies in Chinese 脸红. But some of English expressions involving the color red are nor so easily understood by Chinese. What is the meaning of to see red and waving a red flag? Both are associated with anger.

White To most Chinese and westerners, white has certain similar connotations: purity, innocence, 清白无喜, 洁白. But does that a white lie is supposed to be a harmless one. The connotation of the color white in the Chinese expression 红白喜事 would be confusing to most Westerners. It would not to translate the color at all and merely say weddings and funerals. This is described as happy occasions(喜事) would be absolutely shocking to Westerners, although the expression reflects a certain philosophic.

Black In both English and Chinese there are various terms indicating that black is often associated with negative qualities: blacklist, black market, black-hearted and a number of others. Interestingly, in business of English, in the black has a good meaning; i.e., running a business at a loss, not making profit. These terms came from the color of the ink used in keeping accounts.

Blue In English, blue is usually associated with unhappy feelings. In a blue mood, or having the blues means a sad, gloomy or depressed mood. Blue is also often associated with high social position or being aristocratic. He's a real blue blood means he's from an aristocratic family. Also, in American English, blue book means a book with the name of well-known persons, especially government officials.

Green Besides green with envy, English has the term greened monster or just green-eyed----both means jealous, envious. However, in Chinese, an expression often used to describe envy or jealous is 眼红, 害红眼病. In English, green is also often used to indicate lacking in experience, training or knowledge, as green hand. Similar in meaning is green horn----a person lacking experience, or a newcomer who is not familiar with local customs; the term is used for immigrants and is mildly derogatory.

Yellow Yellow appears in such Chinese expression as 黄色电影, 黄色书刊. Should not be translated as yellow movies, yellow book. Here 黄色 means pornographic, trashy, obscene, filthy, or vulgar. So they are pornographic 
movies, obscene books. Yellow are appear in the English phrase yellow journalism----a kind of journalism with heavy emphasis on scandals, or presenting ordinary news in a sensational manner, sometimes even distorting the facts to create a sensational effect. Also, in most American homes one can find a big thick book called Yellow pages. This is a book with the telephone numbers of different shops, businesses, organization, etc.. It is a useful book. Its pages are yellow, but it is not a 黄色书in the Chinese sense.

\section{B. Metaphor and Association}

People often associate certain qualities with certain creatures or object. These qualities often arouse certain reactions or emotions, although there is little or no scientific ground for such association. The qualities that are associated, or the emotions that are aroused, are not always the same with different peoples. We shall discuss such cultural similarities and/or differences relating to certain birds and animals.

First, let's look into the similarities.

He's as sly as a fox. He's foxy. You've got to watch him.

You ass! You stupid ass! How could you do a thing like that?!

He doesn't have his own idea. He just like parrots what other people say.

The qualities that Chinese associate with the creatures above are roughly the same as those that Americans, Canadians, Englishmen would associate. In fact, in Chinese we have similar expressions; for example, 蚌驴, 鹦武学 舌, 像狐狸一样狡猾.

Other animals that have similar associations in both cultures: deer are meek and gentle; lambs are livable; pigs are dirty and greedy; monkeys are naughty, playful; wolves are bloodthirsty and cruel.

Then we look at the differences. We shall consider two categories:

First, creatures having certain associated characteristics in one culture, but not in the other. Take bull and the crane for example.

To Chinese, the bull carries no particular association. They are merely animals that may or may not be common, may or may not useful. Chinese might be guessing the meaning of a bull in a china shop, but they would not have the image that would be evoked in the minds of English-speaking people: an angry, snorting bull charging into a shop dilled with exquisite fragile porcelain. Consequently, Chinese would be less appreciative of the vividness of the expression - meaning a person who is clumsy and bungling and causes a lot of trouble in a situation requiring tact and delicacy.

The crane is a symbol for longevity in Chinese culture. Thus parents giving names like 鹤年 and 鹤龄 show their hope that the child will live to a ripe old age. The crane is often paired with the tree, which is a symbol for sturdiness and long life. In paintings and art designs, the two often appear together with the motto 松鹤延年. Gifts with such designs are favorites for older people, especially on birthday occasions. But to western minds, the crane does not arouse any such association.

Second, creatures with certain associated qualities in both cultures, but with different qualities. Take the $o w l$ and $d o g$ for example.

As wise as an owl indicates that English-speaking people associate wisdom with this bird. In children's books and cartoons, the owl is usually solemn and wise. In disputes among birds and beasts, it is the owl that acts as judge. In moments of crisis, it is the owl that they go to for advice. Among many Chinese, however, there is a saying 夜猫子进 宅(an owl visiting room), portending misfortune in that household. The mere sight of an owl or the sound of the creature's hooting is enough to cause people to draw back in fear.

Man's best friend is sometimes heard in English conversation or seen in English writing. Many would be surprising that it is the $\operatorname{dog}$. To many Chinese, it would be unthinkable for the dog to be given such honor. Dogs, in China as well: loyalty, dependability, courage, and intelligence. But in China, dogs are first of all watchdogs, not pets. They are kept because they are considered a necessary evil, to be tolerated but not loved.

Lastly, we shall take up two legendary or mythological creatures. In the dynastic times in China, the traditional symbols of royalty were the dragon and phoenix. The dragon stood for the king or emperor, and the phoenix for the queen or empress. There were few negative connotations and even today, these mythological creatures occasionally appear in tradition Chinese designs for it is an auspicious creature that supposedly brings good luck.

However, to westerners, the dragon is often a symbol of evil, a fierce monster that destroys and therefore must be destroyed. Several stories of saints or heroes deal with struggles against the monsters, which is the most case are slain in the end. The phoenix, in Western mythology, is associated with rebirth and resurrection. According to Greek legend, the phoenix lives a certain number of years----500 by one account. At the end of the period, if makes a nest, singing a death song, the sets fire to its nest by flapping its wings. The phoenix is burned to ashes, but from these ashes emerges a new bird.

\section{Idioms, Proverbs and Sayings}

Idioms, proverbs, and sayings are an important part of the language and culture of a society. They are often hard to understand, especially idioms, and harder to use correctly. However, their proper use in a language is often a mark of a person's command of the language. Speech or writing without them lacks color and is uninteresting, but overuse or 
improper use makes the language sound affected and unnatural. It is often said that nothing marks a foreigner more than his unnecessary use of idioms.

Of all different kinds of English idioms, perhaps the hardest to learn are those comprising the forty or so most common verbs in various combinations with about a dozen prepositions or adverbs like up, down, in, out, off. The different meanings of such combinations amount to several hundred, and the confusion that they cause for the learners are immersing.

So, first of all, a student should learn not to look down on such idioms just because they're made up of such simple and easy words. He should look out for identical phrases with different meaning and look them up in the dictionary if he's not sure. He's bound to run into a lot of trouble when he first uses them, but he shouldn't give in, much less give up. If he keeps trying and keeps at it long enough he'll make out and things will turn out in the end. Besides, there are other idioms just as hard for the students to understand, but perhaps not so hard to remember.

Now we shall look at proverbs and sayings. Proverbs are short sayings of folk wisdom - of well-known facts or truths - expresses succinctly and in a way that makes them easy to remember. Because the sayings are so pithy, they have universal appeal. Students love to pick up proverbs, and the use of one or two in the original languages is often a minor triumph for beginning foreign language learners.

Proverbs may provide interesting little glimpses or clues to a people's geography, history, social organization, social views, and attitudes. People who live along seacoast and whose livelihood is dependent on the sea will have proverbs about sailing, about braving the weather, about fish and fishing. Nomadic people, such as the Arabs, have sayings about the desert or pastureland, about sleep and horses or camels, about wolves and wisdom of the elders. And in societies there women's status is low, there will be a number of sayings demeaning them.

Human experiences and observations of the world are in many respects similar. So, in spite of the dissimilar cultural backgrounds of the Chinese and the English-speaking peoples, the number of proverbs or sayings in the two languages that are equivalent or close approximation is rather surprising. Consider the following:

Striking while the iron is hot 趁热打铁

Haste makes waste 欲速则不达

Birds of a feather flock together 物以类聚, 人以群分

Look before you leap 三思后行

Where there smoke, there's fire 无风不起浪

Where there's will, there's a way 有志者事竟成

Given a person a does of his own medicine 以其人之道还治其人之身

All good things must come to an end 天下没有不散的宴席

Since culture is important in giving a language its characteristics, the dissimilarities are naturally more apparent. Compared with English proverbs, the Chinese show certain distinctive features. First of all, the immense number. Chinese seem to have a proverb or saying for almost all conceivable situations----whether they be human-nature situation, or human-human relations. Secondly, the distinctive Chinese quality of many of the sayings: 小卒过河，意 在吃帅 and 挂羊头, 卖狗肉 are typical一the first having its origin in Chinese chess, the second referring to a Chinese butcher's shop with items that would be shocking to the West. Thirdly, the number that reflect social inequalities and the feelings of those deprived and oppressed, such as 卖花姑娘插竹叶, 卖线姑娘裙角裂 or 只许州官放火, 不许百 姓点灯. Fourthly, the influence of Buddhism on Chinese customs and thinking, as in 远看菩萨，近看泥巴 and 平时 不烧香, 临时抱佛脚 where English proverbs reflect the influence of Christianity. Another feature is what might be called social harmony, or brotherhood, or “doing good”; Chinese seem to have more of such proverbs, as 前人栽树, 后人乘凉; 一人掘井, 众人吃水; 一个篱笆三个桩, 一个好汉三个帮。

The points of difference mentioned about are not exhaustive, but will help to give English learners some ideas.

\section{Different Values System}

Value systems are culturally diverse. Furthermore, values are the basis for our action. They guide our behavior and help us determine what is right and what is wrong, what is good and what is bad. They determine differences of communicative speeches among different cultures. From the brief introduction of value systems above, we can see that the essential difference between the Chinese and Western culture is that of value systems. Next, we will illustrate the comparison between value systems of different cultures and explore the roots.

Jia Yuxin (1997) states that values tend to permeate a culture. An understanding of cultural values helps us appreciate the speeches and behavior of other peoples. Cultural values are derived from the larger philosophical issue that has deep roots in the history of countries. Chinese 'indirectness' is a topical subject among westerners in China and those frequently interacting with Chinese. Westerners generally use a direct communication style whereas Chinese usually use an indirect one. Westerners tend to be frank and direct whereas Chinese are polite rather than honest. Chinese usually criticize someone through a third party. On the contrary, westerners usually give direct and frank comments and advice rather than a roundabout way. Indirectness is the most important approach to politeness in China, while directness turns out to be appropriate in the communication in western countries.

Collectivism in Chinese culture is 'we' consciousness and collectivity-orientation whereas the major characteristic of 
individualism in English cultures is ' $\mathrm{I}$ ' consciousness and self-orientation. Self-denigration, mutual care, seeking harmony and moral obligations are common in collective cultures while balance of cost and benefit, respect for individual territory and freedom, and strategy of avoiding conflict are apparent manifestations of individualistic cultures. Collective cultures see the group as the most important of all social entities, from the family to the factory. In individualism culture, competition rather than cooperation is encouraged; personal goals take precedence over group goals; people tend not to be emotionally dependent on organizations and institutions; and every individual has the right to his or her private property, thoughts and opinions.

Because of different history and background, different value systems are shaped. Under the impact of Confucianism in China, benevolence is highly valued and serves the standard as interpersonal relationship, which is based on the fulfillment of the obligations and responsibilities. In the Western culture, each member of the Western society comparatively speaking enjoys independence and equality. In a culture, where equality is as highly valued as it is in the United States, people are expected to take the initiative in advancing their personal interests and well-being and to be direct and assertive in interacting with others.

The Chinese society, traditionally speaking, is hierarchical in nature. There are many vertical or hierarchical relationships, so respect for the elder and authority is much emphasized. In China, people are prone to use honorific titles and respectful words. In order to show respect, people usually say, "How is your family", when they give greetings to each other. What authority refers to vary with time. Nowadays, it may include, for example, father in a family, leaders at different levels, the elder and the aged, and even people who are considered to be useful in the society (Jia, 1997). Authority is respected and listened to and power relationship is in the use of titles or honorifics when addressing occurs.

Respect is the predominant norm or value orientation in Chinese, just as change and progress is the important value orientation in the Western culture. These beliefs and attitudes produce a certain mind-set and a wide range of speech patterns. Various aspects of this orientation are optimism, receptivity to change, emphasis on the future rather than the past or present. The value systems influence their attitudes to life and work. Americans tend to be changeable. The young usually do not live with their parents. They are independent and rebellious. Creativity is highly valued, so the common people are not required to listen to their authority. The difference between value systems fosters not only the different beliefs but also the speeches.

\section{WAYS TO IMPROVE ENGLISH MAJORS' ABILITY TO UNDERSTAND WORDS' CULTURAL CONNOTATION}

As what has be discussed above, the cultural connotation of words is closely related to their ability to understand words well. If they know the cultural connotation of words, they will understand the words better. However, if they lack the ability, understanding the word well will be difficult or impossible because of the negative transfer of culture. Therefore, the teacher should find ways to fill in the important gaps in the cultural connotation of words.

\section{A. Cultivating Cultural Creativity}

Gaining knowledge about foreign culture in EFL learning, and further empowered by action to interact, the learner's relations with reality have started to change. He or she may view the world differently. To accelerate this change, we should introduce the concept of "generative learning" to learners in China. In generative learning, students are encouraged to go beyond the known to the unknown. In this process, they will see how they themselves acted while actually experiencing the situation they are now analyzing, and thus reach a "perception of their previous perception." This step is significant. By achieving this awareness, they come to perceive reality differently: by broadening the horizon of their perception, they discover more easily in their "background awareness" the dialectical relations between the two dimensions of reality.

If learners are able to gain insight into their previous perceptions and to inquire into their previous knowledge and experience, a change is in the making, because change is made on the basis of critique of conventions. If Chinese learners, through learning EFL, have develop a creative power for change, the perhaps we can say they have what we called culture creativity.

\section{B. Participating in Practice}

The next step in the learner's internal change through EFL learning is: from being knowledge to being flexible and open to new experiences. The most effective way for a Chinese EFL learning to develop an understanding of foreign culture is probably to participate in the community in its cultural environment. But as we know, this is unrealistic for most EFL learning in China. But that does not mean that the learner cannot be a "participant".

Classroom as culture is a real environment where the learner may begin to understand the foreign culture. According to this point of view, the classroom is an artificially created cultural environment in which the learner's internal social reality meets a different external reality. By participating in classroom interaction, the learner's knowledge is employed to match new input. A process of learning takes place in the process of interaction. In foreign language class, culture is created and enacted through the dialogue between students and between teacher and student. Through their dialogue, participants not only replicate a given context of culture, but because it takes place in a foreign language, it also has the potential of shaping a new culture. 
Besides, there are many ways to learn the foreign culture. Talking to the native English speakers is the best idea to improve one's oral English, through talking, at the same time, one can get the real feeling through talking.

The process of acquitting knowledge about foreign culture and using this knowledge in actual behavior is also a process of cultural interaction in which both home and foreign cultures are brought together. The learner's own patterns of behavior are learned through their life experiences in China. The new experiences, which they received from learning and using EFL, will be filtered through their existing background knowledge. The key to acquiring the broad patterns of behavior lies in some experts called "interpretative repertoires" which are shared conceptual frameworks or recurrently used systems of terms applied in characterizing and evaluating actions, events and other phenomena. Since these "interpretative repertoires" cannot be described in words, the only way of learning is to engage in various kinds of social interaction.

\section{CONCLUSION}

Cultural teaching does indeed occupy a place in the English vocabulary teaching. For example, culture can not only provide a key to understanding English words well but it is also an ideal vehicle for improving their ability of translating, reading and writing. The success in teaching vocabulary well greatly depends upon teacher's telling. And other ways, such as discussion, literature, films are also important in introducing culture to students and furthermore improving their ability of mastering words. Cultures differ from one another each culture is unique. Learning words well means more than merely mastering the pronunciation, grammar but also mastering the cultural background and their ideas, customs and their "language of mind". This paper analyses the relationship between culture and vocabulary, problems caused by different cultural connotation in vocabulary understanding and also some suggestions on how to teach word's cultural connotation well. And I hope all of these will help to improve English majors' ability of mastering word's meaning and furthermore to have successful communication with foreigners in their work in the future.

\section{REFERENCES}

[1] Chen Yuan. (1983). Sociolinguistics. Shanghai: Academic Press.

[2] David Wilkins. (1972). Linguistics \& Language Teaching. London: Edward Arnold.

[3] Deng Yanchang, Liu Runqing. (2007). Language \& Culture. Beijing: Foreign Language Teaching \& Research Press.

[4] EugeneA.Nida. (1991). Language, Culture and Translation. Shanghai: Shanghai Foreign Language Education Press.

[5] Gao Jili. (2002). Improving Chinese EFL Students' Reading Comprehension Through Developing Background Knowledge. Teaching English in China Quarterly, 25(3),54-57.

[6] Jia Yuxin. (1997). On Cross Cultural Communication. Shanghai: Shanghai Foreign Language Education Press.

[7] Liu Shuang. (1995). Function of Culture in the Understanding of Words. Foreign Language Research, 4, 45-47.

[8] Yu Lihua. (2004). The Necessity of Cultural Introduction in English Teaching for Non-English Majors. CELEA Journal Bimonthly, 27, 104-108.

[9] Wang Rongpei. (2002).Courses of English Lexicology. Shanghai: Shanghai Foreign Language Education Press.

Xianmei Sun was born in Dezhou, China in 1964.She received her bachelor degree in linguistics from Qufu University, China in 1984.

She is currently an associate professor in the Department of Foreign Language, Dezhou University, Shandong, China. Her research interests include English teaching methodology and applied linguistics.

Ms. Sun is a member of the Chinese Semiology Association of Foreign Language Teachers. 